\title{
SCIDiC
}

International Journal of Bone and Rheumatology Research (IJBRR)

ISSN: $2470-4520$

\section{Rotating-Hinge Knee Prosthesis in Treatment of Malignant Tumors Around the Knee Joint: Clinical and Functional Outcomes with A Literature Review}

Hatim ABID*, Mohammed EL IDRISSI, Abdelhalim EL IBRAHIMI, Abdelmajid ELMRINI

Department of Osteoarticular Surgery B4, HASSAN II Teaching Hospital, Fes, Morocco.

Abstract

\begin{abstract}
Reconstruction for malignant tumors around the knee after wide resection constitutes a real surgical challenge. We evaluated by referring to literature data, the 3 year results of tumoral resection and joint reconstruction using rotating-hinge knee. There were 12 distal femoral and tibial proximal replacements. Clinical and functional outcomes obtained were comparable to those of the literature. Our prosthetic survival was $75 \%$.
\end{abstract}

Keywords: Malignant Bone Tumor; Rotating-Hinge Knee; Prosthesis; Outcomes; Complications.

\section{Introduction}

Segmental resections and joint reconstruction used to treat malignant tumors around the knee joint offer several advantages including maintenance of motion and early functional restoration $[1,2]$. The rotating-hinge knee prosthesis that combines movement in 3 directions (flexion-extension, rotation, and distraction) allows dispersing stresses throughout the components, reduces constraints on the bone-implant interface [3] and permits weight bearing throughout the tibial articulation. We report through this article, the clinical and functional outcomes of 12 patients followed for malignant tumors around the knee, treated by rotatinghinge knee prosthesis during the last 3 years from January 2017 to December 2019.

\section{Patients and Method}

In the present study, the authors performed a retrospective study of the outcomes in patients diagnosed with malignant tumor around the knee joint treated in the department of orthopedic surgery B4 of the University Hospital of Fez (Morocco) with rotating-hinge knee prosthesis (Figure 1). There were 12 distal femoral and proximal tibial replacements. The tumor diagnosis was osteosarcoma in 8 cases, chondrosarcoma in 2 cases and malignant giant cell tumor in 2 patients (Figure 2 and 3). According to the TNM classification [4], at the time of the initial di- agnosis, 6 patients were stage IB, 5 patients were stage IIB, and 1 patient was stage III [4]. At the time of the initial evaluation, all patients underwent a thorough oncologic examination, which included chest radiography, computed tomography, and magnetic resonance imaging (MRI). There were no distant metastases of the primary musculoskeletal tumor at the time of reconstructive surgery. Excision was performed through a medial parapatellar approach including the previous biopsy site. Uninvolved vastus muscle was spared, and a 2 centimeters bone and muscle margin was taken around the tumor (Figure 4). Preoperative and postoperative chemotherapy was used in 5 patients. Three patients had preoperative radiation therapy. Clinical data were retrieved from the clinical charts, radiographs and outpatient interviews. The median tumor size was $8 \mathrm{~cm}$. Five tumors were epiphyseal and the remainder metaphyseal. Function was assessed by the criteria of the Musculoskeletal Tumor Society (MSTS) [4]. Seven items were analyzed for this, which are movement, pain, stability, deformation, strength, functional activities and emotional acceptance of reconstruction by the patients. Radiographic assessment followed the guidelines proposed by the International Symposium on Limb Salvage (ISOLS) [5] based on 6 parameters, namely, bone remodeling, interface, anchorage, implant body problem, implant articulation, and extracortical bone bridging. In terms of complications, we deplore two cases of skin necrosis associated with early infection and 1 case of aseptic loosening.

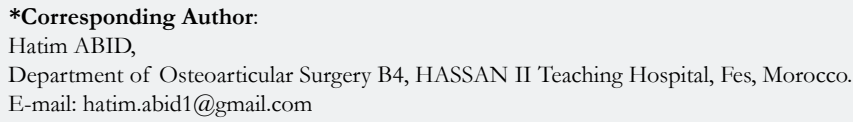

Citation: Hatim ABID, Mohammed EL IDRISSI, Abdelhalim EL IBRAHIMI, Abdelmajid ELMRINI. Rotating-Hinge Knee Prosthesis in Treatment of Malignant Tumors Around the Knee Joint: Clinical and Functional Outcomes with A Literature Review. Int J Bone Rheumatol Res. 2020;5(3):92-95. doi: http://dx.doi.org/10.19070/2470-4520-2000019

Copyright: Hatim ABID $^{\circ}$ 2020. This is an open-access article distributed under the terms of the Creative Commons Attribution License, which permits unrestricted use, distribution and reproduction in any medium, provided the original author and source are credited. 
Figure 1. Image of Rotating-hinge knee prosthesis.

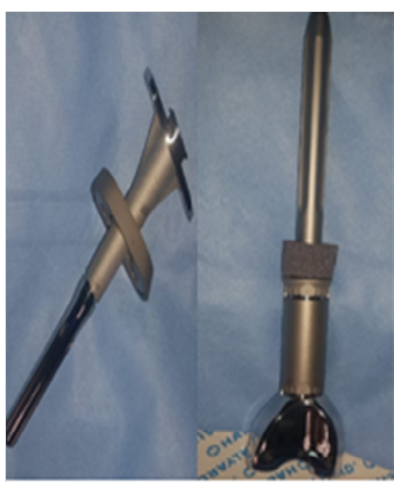

Figure 2. Intraoperative view of a giant cell malignant tumor of the right knee.

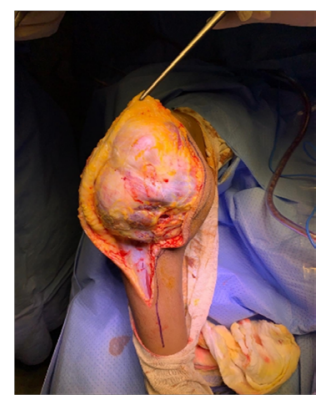

Figure 3. Image of a giant cell tumor of the proximal tibia after resection.

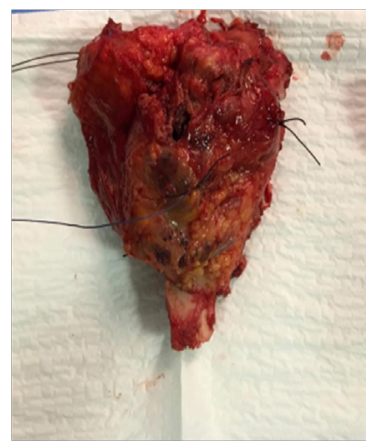

Figure 4. Intraoperative view of Rotating-hinge knee prosthesis in place after tumoral resection and joint reconstruction.

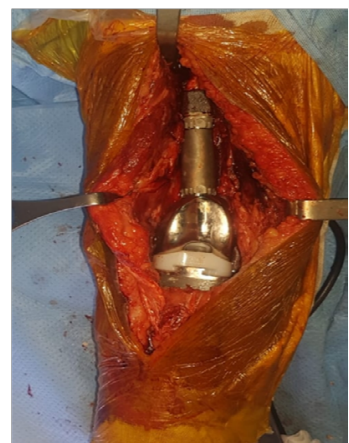

\section{Results}

\section{Function}

The arc of motion at the latest follow-up ranged from $20^{\circ}$ of extension to $130^{\circ}$ of flexion with a median of $110^{\circ}$. According to the Musculoskeletal Tumor Society (MSTS) evaluation system, functional score ranged from 12 to 30 with 23 of a mean (Table 1). The salvaged limb was painless in 8 patients $(67 \%)$, and $4 \mathrm{pa}-$ tients $(33 \%)$ had no functional restriction. Two patients who had a resection of an osteosarcoma, presented postoperatively skin necrosis and early infection managed by complete prosthetic ex- change and local rotation muscle flap to cover the prosthesis with vascularized tissue. The third patient had a resection of malignant giant cell tumor from the distal femur and developed aseptic loosening of the femoral component at the latest follow-up which was 30 months on average. At the time of last follow-up, 9 patients were continuously disease free, 2 were alive with metastatic disease, and 1 patient had died of disease. None of the patients in the study group developed local recurrences.

\section{Radiographic Evaluation}

Radiographs were available for all patients. The analysis was rated 
Table 1. The Mean Musculoskeletal Tumor Society (MSTS) Functional Score.

\begin{tabular}{|c|c|}
\hline parameters & Mean of MSTS functional score \\
\hline Movement & 3 \\
\hline Pain & 3.1 \\
\hline Stability & 3.3 \\
\hline deformation & 3.2 \\
\hline strength & 3.2 \\
\hline functional activities & 3.2 \\
\hline $\begin{array}{c}\text { emotional accept- } \\
\text { ance }\end{array}$ & 4 \\
\hline Total & 23 \\
\hline
\end{tabular}

as good to excellent scores with regard to bone remodeling, interface radiolucent lines and anchorage. Nine patients were rated as excellent and good with regard to bone remodeling. The patient who had revision surgery for aseptic loosening was rated as poor with regard to the prosthetic-bone interface. Magnetic resonance imaging (MRI) for detection of local recurrence and chest computed tomography (CT) for lung metastasis were routinely arranged every 3 months in the first 2 years and every 6 months beyond. In our series, the prosthetic survival without clinical or radiographic failure was $75 \%$ at 3 years.

\section{Discussion}

Reconstruction for malignant tumors around the knee after wide resection remains a challenging problem. In this context, prosthetic replacement offers several advantages including early stability and mobilization which are especially important for patients with life-threatening malignant bone tumors. Since 1975, many various models of hinge knee prostheses were developed and used.

From a biomechanical point of view, Ward et al., [6] reported in 2003 an analysis of the third generation of rotating hinge Total Knee Arthroplasty (TKA). The study showed that prosthesis with shorter and markedly tapered pegs could become unstable under mild joint distraction. In 2013, Friesenblicher et al., [7] evaluated stability of rotating hinge knee prostheses (Figure 3). They found that the long and cylindrical pegs offer the highest stability at any given level of distraction.

In their beginning, tumor prostheses were produced in monoblock form of cast steel alloys. Then material evolution was made towards titanium and cobalt-chrome molybdenum. To address of requisites in resistance to corrosion, biocompatibility, resistance to fatigue fractures and higher potential of osteointegration, the development of the metallurgical industry and prosthesis design have providing a variety of coatings, fixing materials and implant geometry which have significantly improved stability and longevity of prostheses $[8,9]$.

The complication rate after prosthetic replacement remains high. The rate of infection ranged from $3 \%$ to $22 \%$ in previous reports $[10,11]$. Haijie et al., [12] showed that the mean incidence of infection was $8.5 \%$ and $16.8 \%$ for respectively distal femoral and proximal tibial replacement.
Structural failures are not an uncommon complication after tumor prosthesis implantation. The most common site of breakage often reported is the stem collar junction. In this context, Agarwal et al., [13] identified 28 breakages in 266 megaprosthetic knee arthroplasties which achieves a rate of $10 \%$. Capanna et al., [14] evaluated 200 megaprostheses in lower limb reconstruction after tumor resection at a minimum follow-up of two years. The authors observed structural failures in $7 \%$ of the cases. Bus et al [15] reported at the same time $14 \%$ of structural failure after a mean of three years.

In most cases following wide excision of high-grade sarcomas, soft tissue stability is difficult to maintain. In these cases, rotating-hinge knee prostheses provide the stability required for arthroplasty. When there is greater force transmitted to the fixation interfaces, premature aseptic loosening is highly favored $[16,17]$. In various studies, the rate of this complication varied between 5 and $48 \%[18-21]$.

Skin necrosis is one of the most daunting complications of reconstruction for malignant tumors around the knee after wide resection. Postoperative wound complications developed more frequently after extra articular resections. The incidence of skin complications is around $12.5 \%$ for Kawai et al., [21] and ranges from $0.33 \%$ to $10.5 \%$ for Galat et al., [23] and Gaine et al [23]. Factors that increase the risk of skin necrosis after tumor prosthesis can be systemic including smoking, diabetes mellitus, increasing patient age, obesity, immunocompromised state, preexisting peripheral vascular disease, malnutrition, chronic renal insufficiency, and chemotherapy, or local factors represented by dystrophic skin, hematoma, prior surgery on the affected knee, and prior skin irradiation.

Regarding implant survival, the values are very variable. Many reports described 5 year overall survival rates of $32 \%$ to $44.5 \%$. At 10 years, Kalra et al., [10] reported a survival rate of $37 \%$. Otherwise, survival rates were higher in other series such as that of Shehadeh et al [18] which reported $84 \%$ at 5 years, $72 \%$ at 10 years and $37 \%$ at 20 years. In terms of factors influencing implant survival, the authors reported surgery methods, lung metastasis, clinical stage and cycles of chemotherapy [24-26].

In the present study, tumoral resection and joint reconstruction using rotating-hinge knee prosthesis were performed safely and successfully. Our clinical and functional outcomes obtained were comparable to those of the literature. It was the same for the rate 
of infection, skin necrosis, structural failures and aseptic loosening. As a reminder our prosthetic survival without clinical or radiographic failure was $75 \%$ at 3 years.

\section{Conclusion}

Rotating-hinge knee prostheses represent a gold standard in oncologic orthopedic surgery, as they facilitate efficient reconstruction of large skeletal resection, combined with high limb salvage rate. With great conviction, we adopt this saving attitude offering a good quality of life to the patients with a view to a prospective study with longer following up and a greater number of patients.

\section{References}

[1]. Capanna R, Morris HG, Campanacci D, Del Ben M, Campanacci M. Modular uncemented prosthetic reconstruction after resection of tumours of the distal femur. J Bone Joint Surg Br. 1994 Mar; 76(2): 178-86. PMID: 8113272.

[2]. Damron TA. Endoprosthetic replacement following limb-sparing resection for bone sarcoma. Semin Surg Oncol. 1997 Jan-Feb; 13(1): 3-10. PMID: 9025176.

[3]. Eckardt JJ, Eilber FR, Kabo JM, Mirra JM. Kinematic rotating hinge kneedistal femoral replacement. Limb Salvage in Musculoskeletal Oncology. New York, Churchill Livingstone. 1987: 392-409.

[4]. Edge SB, Compton CC. The American Joint Committee on Cancer: the 7th edition of the AJCC cancer staging manual and the future of TNM. Ann Surg Oncol. 2010 Jun;17(6):1471-4. PMID: 20180029.

[5]. Enneking WF, Dunham W, Gebhardt MC, Malawar M, Pritchard DJ. A system for the functional evaluation of reconstructive procedures after surgical treatment of tumors of the musculoskeletal system. Clin Orthop Relat Res. 1993 Jan; 286: 241-6. PMID: 8425352.

[6]. Ward WG, Haight D, Ritchie P, Gordon S, Eckardt JJ. Dislocation of rotating hinge total knee prostheses. A biomechanical analysis. J Bone Joint Surg Am. 2003 Mar;85(3):448-53. PMID: 12637430.

[7]. Friesenbichler J, Leithner A, Glehr M, Sadoghi P, Maurer-Ertl W, Avian A, Windhager R. Evaluation of stability of rotating hinge knee prostheses: a biomechanical study. ISRN Orthop. 2013 Jul 18;2013:701693. PMID: 24967114

[8]. Choong PF, Sim FH, Pritchard DJ, Rock MG, Chao EY. Megaprostheses after resection of distal femoral tumors. A rotating hinge design in $30 \mathrm{pa}-$ tients followed for 2-7 years. Acta Orthop Scand. 1996 Aug; 67(4): 345-51. PMID: 8792736.

[9]. Schwartz AJ, Kabo JM, Eilber FC, Eilber FR, Eckardt JJ. Cemented distal femoral endoprostheses for musculoskeletal tumor: improved survival of modular versus custom implants. Clin Orthop Relat Res. 2010 Aug; 468(8): 2198-210. PMID: 20033359.

[10]. Kalra S, Abudu A, Murata H, Grimer RJ, Tillman RM, Carter SR. Total femur replacement: primary procedure for treatment of malignant tumours of the femur. Eur J Surg Oncol. 2010 Apr; 36(4): 378-83. PMID: 20230929.

[11]. Ahmed AR. Total femur replacement. Arch Orthop Trauma Surg. 2010 Feb;
130(2): 171-6. PMID: 19644695.

[12]. Puri A, Gulia A, Chan WH. Functional and oncologic outcomes after excision of the total femur in primary bone tumors: Results with a low cost total femur prosthesis. Indian J Orthop. 2012 Jul; 46(4): 470-4. PMID: 22912524.

[13]. Haijie L, Dasen L, Tao J, Yi Y, Xiaodong T, Wei G. Implant Survival and Complication Profiles of Endoprostheses for Treating Tumor Around the Knee in Adults: A Systematic Review of the Literature Over the Past 30 Years. J Arthroplasty. 2018 Apr; 33(4): 1275-1287. PMID: 29191444.

[14]. Agarwal M, Gulia A, Ravi B, Ghyar R, Puri A. Revision of broken knee megaprostheses: new solution to old problems. Clin Orthop Relat Res. 2010 Nov; 468(11): 2904-13. PMID: 20544320.

[15]. Capanna R, Scoccianti G, Frenos F, Vilardi A, Beltrami G, Campanacci DA. What was the survival of megaprostheses in lower limb reconstructions after tumor resections? Clin Orthop Relat Res. 2015 Mar; 473(3): 820-30. PMID: 24964884.

[16]. Bus MP, van de Sande MA, Fiocco M, Schaap GR, Bramer JA, Dijkstra PD. What Are the Long-term Results of MUTARS Modular Endoprostheses for Reconstruction of Tumor Resection of the Distal Femur and Proximal Tibia? Clin Orthop Relat Res. 2017 Mar; 475(3): 708-718. PMID: 26649558.

[17]. Cameron HU, Jung YB. Hinged total knee replacement: indications and results. Can J Surg. 1990 Feb; 33(1): 53-7. PMID: 2302602.

[18]. Bargar WL, Cracchiolo A, Amstutz HC. Results with the constrained total knee prosthesis in treating severely disabled patients and patients with failed total knee replacements. J Bone Joint Surg Am. 1980; 62(4): 504-12. PMID: 7380852.

[19]. Shehadeh A, Noveau J, Malawer M, Henshaw R. Late complications and survival of endoprosthetic reconstruction after resection of bone tumors. Clin Orthop Relat Res. 2010 Nov; 468(11): 2885-95. PMID: 20625951.

[20]. Höll S, Schlomberg A, Gosheger G, Dieckmann R, Streitbuerger A, Schulz $\mathrm{D}$, et al. Distal femur and proximal tibia replacement with megaprosthesis in revision knee arthroplasty: a limb-saving procedure. Knee Surg Sports Traumatol Arthrosc. 2012 Dec; 20(12): 2513-8. PMID: 22392068.

[21]. Wirganowicz PZ, Eckardt JJ, Dorey FJ, Eilber FR, Kabo JM. Etiology and results of tumor endoprosthesis revision surgery in 64 patients. Clin Orthop Relat Res. 1999 Jan; 358: 64-74. PMID: 9973977.

[22]. Kawai A, Muschler GF, Lane JM, Otis JC, Healey JH. Prosthetic knee replacement after resection of a malignant tumor of the distal part of the femur. Medium to long-term results. J Bone Joint Surg Am. 1998 May; 80(5): 636-47. PMID: 9611024.

[23]. Galat DD, McGovern SC, Larson DR, Harrington JR, Hanssen AD, Clarke HD. Surgical treatment of early wound complications following primary total knee arthroplasty. J Bone Joint Surg Am. 2009 Jan; 91(1): 48-54. PMID: 19122078.

[24]. Gaine WJ, Ramamohan NA, Hussein NA, Hullin MG, McCreath SW. Wound infection in hip and knee arthroplasty. J Bone Joint Surg Br. 2000 May; 82(4): 561-5. PMID: 10855883.

[25]. Faisham WI, Mat Saad AZ, Alsaigh LN, Nor Azman MZ, Kamarul Imran M, Biswal BM. Prognostic factors and survival rate of osteosarcoma: A single-institution study. Asia Pac J Clin Oncol. 2017 Apr; 13(2): e104-e1 10 PMID: 25870979.

[26]. Yao W, Cai Q, Wang J, Gao S. Treatment of osteosarcoma around the knee in skeletally immature patients. Oncol Lett. 2017 Nov; 14(5): 5241-5248. PMID: 29113159. 